\title{
Influence of Sodium Hypochlorite-Based Irrigants on the Susceptibility of Intracanal Microbiota to Biomechanical Preparation
}

\author{
Janir Alves SOARES ${ }^{1}$ \\ Donaldo Rosa PIRES JÚNIOR ${ }^{2}$ \\ ${ }^{1}$ Discipline of Endodontics, Department of Dentistry and ${ }^{2}$ Discipline of Microbiology, \\ Department of Science of the Heath, Federal University of Vales do Jequitinhonha e Mucuri, Diamantina, MG, Brazil
}

\begin{abstract}
This study evaluated the microbiological conditions of root canals, using smears and culture from anterior teeth and premolars with necrotic pulps associated with chronic periapical pathologies, before and after biomechanical preparation (BMP). During double-flared instrumentation, 1, 2.5 and 5\% sodium hypochlorite $(\mathrm{NaOCl})$-based irrigants were used in 3 groups: GI ( $\mathrm{n}=39)$, GII ( $\mathrm{n}=36)$ and GIII $(\mathrm{n}=36)$, respectively. Before BMP, all cultures were positive and the smears showed microbiologically diverse morphotypes, including fusiforms, pleomorphic, rods, cocci and filaments. Quantitetively, 20, 20 and 23 morphotypes were identified in GI, GII and GIII, respectively). After BMP, the percentages of negative cultures in GI, GII and GIII were $74.2 \%, 86.3 \%$ and $93.4 \%$ ( $p>0.05$ ) and the number of morphotypes decreased to 14, 15 and 5, respectively. All teeth with 2 root canals and/or associated fistulas were microbiologically negative after BMP, regardless of irrigant concentration. Gram-negative morphotypes were more susceptible to the action of irrigants. After irrigation with $5 \% \mathrm{NaOCl}$, only structural arrangements consisting of Gram-positive cocci and bacilli persisted. Thus, BMP plus $5 \% \mathrm{NaOCl}$ offered the best antiseptic potential because in the few positive cultures a significant reduction in the number of microbiological morphotypes was also shown $(\mathrm{p}<0.05)$.
\end{abstract}

Key Words: root canal therapy, biomechanical preparation, irrigating solutions, microorganisms, sodium hypochlorite.

\section{INTRODUCTION}

The root canals of teeth with necrotic pulps associated with periapical pathology contain decomposed pulp and a diverse reservoir of microorganisms as well as byproducts from pulp necrosis and bacterial metabolism (1). These microorganisms are mainly those that inhabit the oral cavity, the upper respiratory tract or the gastrointestinal system. The number of species identified in the mouth can reach over 530. Of this group, more than one third has already been isolated from root canals (2). Endodontic infection is endogenous and predominantly polymicrobial and a possible correlation has been proposed between the magnitude of radiographic alteration and both the quantity and diversity of the endodontic microbiota (3).

With respect to morphotypes and their staining reactions, most are Gram-positive cocci and Gram- negative bacilli. The intracanal microbiota is also characterized by its dynamics, presenting qualitative and quantitative alterations in response to the ecological conditions in the root canal, which include changes in the availability of carbohydrates, proteins, glycoproteins, oxygen and the oxy-reductive potential. Consequently, selective mechanisms regulate the evolution of endodontic infection in which inter-species affinities and the availability of nutrients are primary determinants of the development of infection and its pathogenicity $(3,4)$. Therefore, due to different evolutionary phases, rarely is the same microbiota recovered from different root canals. These highly coordinated events can respond to a possible topographical and organizational distribution of microorganisms along the canal. Using Brown \& Brenn staining, Soares et al. (4) found in the root canal system of the dogs' teeth a higher prevalence of Gram-positive cocci, bacilli and filaments organized

Correspondence: Prof. Dr. Janir Alves Soares, Universidade Federal dos Vales do Jequitinhonha e Mucuri, Campi I, Rua da Glória, 187, 39100-00 Diamantina, MG, Brasil. Tel: +55-38-3531-2901. Fax: +55-38-3531-1811. email: janirsoares@citel1.com.br 
in amorphous exopolysaccharide structures, adhering to dentin surfaces (biofilms). A scanning electron microscopic study (5) showed a high incidence of straight and curved bacilli, cocci, spirochetes, coco-bacilli rods and filaments, as well as microcolonies composed of cocci, bacilli or yeasts in the apical third of root canals associated with periapical lesions. Sen et al. (6) have reported structural arrangements of a corn-cob structure and Nair (7) identified cellular arrangements in hyphal-like or palisade-like structures.

Classic studies have shown the role of microorganisms in formation of chronic abscesses, cysts and periapical granulomas. Endodontics has sought an effective method to control intracanal infection $(1,8)$. Initially, control of root canal microbiota was predominantly based on locally applied medication. Only after a long time and innumerable changes of balls of cotton wool or paper points soaked in a variety of antiseptic substances, biomechanical preparation (BMP) was introduced to endodontic therapy, representing a significant advance in the control of microorganisms that are the focus of infection (4).

In an effort to remove organic material, microorganisms and their toxins, numerous types of irrigating solutions have been proposed, which in conjunction with the mechanical action of files and reamers, have achieved a satisfactory debridement and antisepsis of root canals (1). Sodium hypochlorite $(\mathrm{NaOCl})$-based solutions have been the most commonly recommended since the 1950s, although there has been no consensus about the best concentration to use (8). Considering that most of its properties are influenced by free chlorine concentration, the purpose of this study was to evaluate the antiseptic effect of various $\mathrm{NaOCl}$-based irrigants used for BMP of root canals associated with chronic periapical pathologies in asymptomatic patients.

\section{MATERIAL AND METHODS}

Patients treated at the Clinic of Endodontics of Federal University of Vales do Jequitinhonha e Mucuri (Brazil) were enrolled in this study. The research project was approved by the Ethics in Research Committee and the patients signed an informed consent form.

The sample comprised 93 anterior teeth and premolars with advanced carious lesions, necrotic pulp and periapical radiolucences, from 83 asymptomatic patients aged 14-53 years, making a total of 111 root canals randomly assigned to 3 groups: I ( $n=39)$, II ( $n=36)$ and III ( $\mathrm{n}=36)$, with 31,32 and 30 teeth, respectively.

After rubber dam isolation and antisepsis of the operating field with $5.0 \%$ iodated alcohol solution plus neutralization with alcohol/ether, coronal pulp chamber was opened and irrigated with sterile saline. Based on a diagnostic radiograph, the root canals were explored with sizes 10, 15 or 20 K-type files (Dentsply/Maillefer, Ballaigues, Switzerland) up to $3 \mathrm{~mm}$ short of the tooth radiographic length (TRL). Another radiograph was taken and root canal length was corrected. All canals were initially explored up to the radiographic vertex, i.e. to the extent of root canal patency length (CPL). Next, microbiological collection was done by introduction of 3 sterile absorbent paper points, each for $1 \mathrm{~min}$. From each canal were obtained 3 smears that were Gram stained. Microbiological samples were placed in culture medium based on a brain-heart infusion (BHI; Difco, Detroit, MI, USA) and thioglycollate broth (Difco), followed by aerobic incubation for $48 \mathrm{~h}$, and microaerophilia by the candle jar system at $37^{\circ} \mathrm{C}$ for a minimum of $72 \mathrm{~h}$. Subsequently, the root canals of groups I, II and III were irrigated with 1.0, 2.5 and 5.0\% $\mathrm{NaOCl}$, respectively. BMP was undertaken according to hybrid technique principles, using step-down followed by step-back instrumentation. The working length (WL) was established at $1 \mathrm{~mm}$ short of the CPL. KFlexofiles (Dentsply/Maillefer) were used in an oscillating gyratory movement. Using a Luer Lock syringe with a 30/6 needle positioned close to the WL, the canals were irrigated with $3.0 \mathrm{~mL}$ of the solution after each endodontic file used. To increase the contact of the solution with the canal and its contents, a small diameter file (sizes 06,08 or 10) was stirred making 10 to 15 clock-wise circular movements, repeated in an anticlockwise direction, for nearly $10 \mathrm{~s}$. After irrigation and aspiration, the WL was enlarged at least to a size 35 file. After removal of the smear layer by irrigation with $3 \mathrm{~mL}$ of $17 \%$ EDTA and introduction of the master apical file for 5 min plus irrigation with $\mathrm{NaOCl}$, the canals were copiously irrigated with $5 \mathrm{~mL}$ sterile saline. With the canals still moistened with saline, the second microbiological collection was done with absorbent paper points, as previously described, whose diameters corresponded to the apical enlargement pattern. The absorbent paper points were transferred to a culture medium that was incubated according to previous instructions, as well as for the acquisition of smears. From positive cultures, 5 
smears were prepared and Gram stained. Using an immersion optical microscope, the morphotypes were recorded (approximately 20 fields per slide). The number of microbial morphotypes in the root canals before and after BMP, as well as the incidence of negative microbiological culture after BMP, were analyzed statistically by the chi-square test at $5 \%$ significance level.

\section{RESULTS}

The results are presented on Tables 1, 2 and 3 . In the first microbiological evaluation all samples had microorganisms, but a larger number of morphotypes were identified in the primary root canal smears. In contrast, in the second microbiological evaluation, a larger number of morphotypes were identified in the cultures. Before BMP, 24 microbiological morphotypes

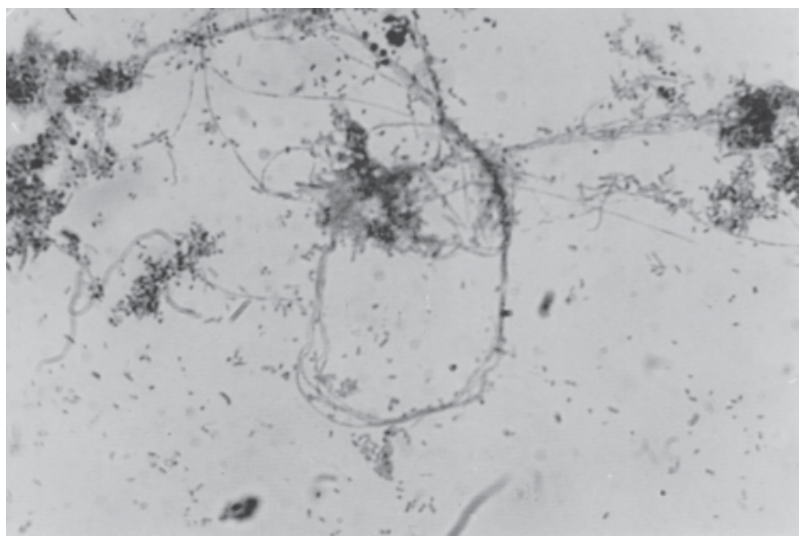

Figure 1. Cocci and bacilli within extensive interlaced filaments.

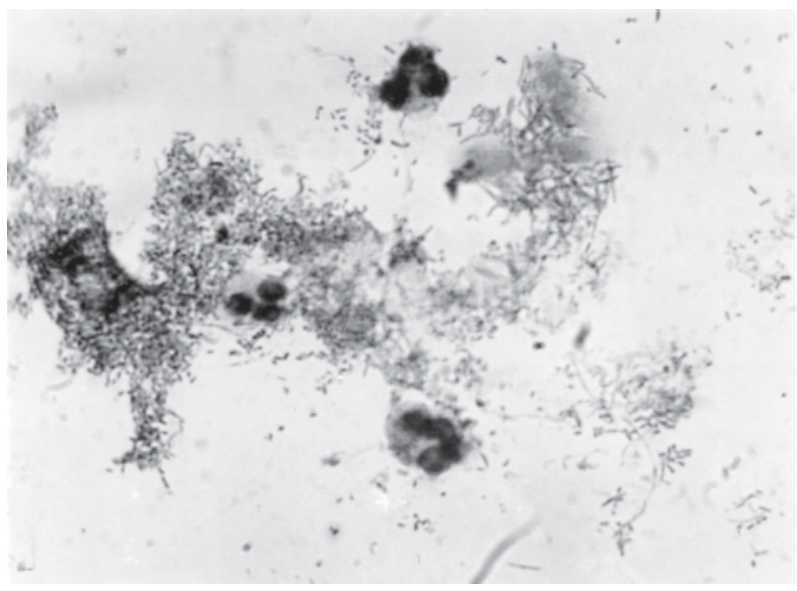

Figure 2. Uncountable cocci, bacilli, filamentous microorganisms, pseudo-hyphae and some neutrophils. (see examples on Figs. 1-3) were identified from 111 root canals (Tables 1 and 3 ). The number of morphotypes ranged from 2 to 16 per root canal, median of 10 (Table 3). After BMP, root canals in groups I, II and III were $74.2 \% ; 86.3 \%$ and $93.4 \%$ microbiologically negative respectively, but without significant difference $\left(\chi^{2}=4.0\right.$; $\mathrm{p}=0.1351)$ (Table 2). After BMP, 92.6\% of the cultures of the 15 microbiologically positive root canals remained polymicrobial. The cultures obtained after BMP revealed 16 microbiological forms, 14, 15 and 5 morphotypes being recovered in groups I, II and III, respectively (Table 2). The 18 teeth with two root canals had negative microbiological culture after BMP irrespective of the irrigant. Similar result was found for the 18 teeth with sinus tract (Table 3). After BMP, the predominant microorganisms in Group I were: Grampositive rods, staphylococci, Gram-positive streptococci and diplococci. Group II revealed Gram-positive cocci in isolation or in chains, Gram-positive fusiforms, Gram-positive filaments and Gram-positive diplobacilli and streptococci. Group III revealed Gram-positive Vshaped rods, Gram-positive cocci in isolation or in chains, Gram-positive diplococci and staphylococci occurred at the same frequency (Table 1).

\section{DISCUSSION}

All teeth with necrotic pulp associated with periapical radiolucent areas had a variable number of microbiological morphotypes in the root canal, mainly rods, cocci, fusiforms and filaments, Gram-positive

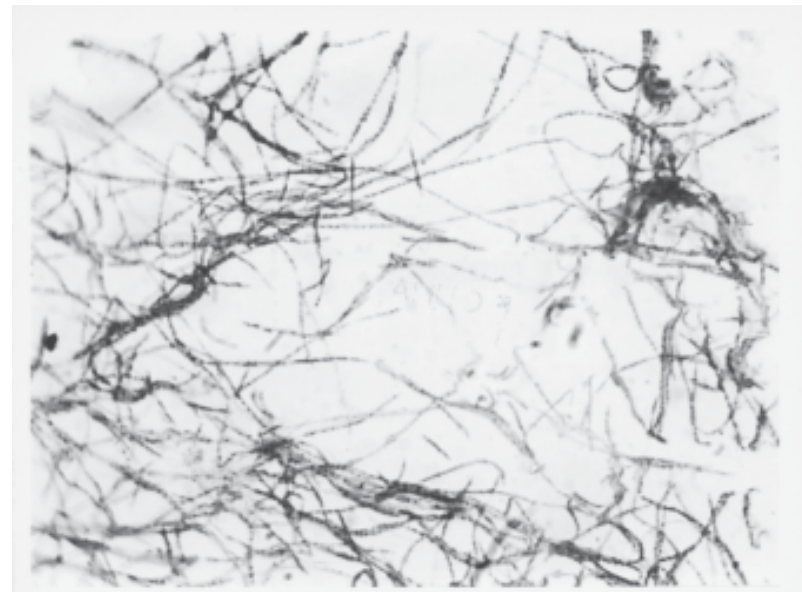

Figure 3. Fungi. Note the interlacing of extensive filaments (hyphae). 
Table 1. Relative and absolute incidence of microbial morphotypes, in root canals before and after biomechanical preparation in the 3 experimental groups.

\begin{tabular}{|c|c|c|c|c|c|c|}
\hline \multirow[t]{2}{*}{ Morphotypes } & \multicolumn{2}{|c|}{ Group I ( $\mathrm{n}=39)$} & \multicolumn{2}{|c|}{ Group II $(n=36)$} & \multicolumn{2}{|c|}{ Group III (n=36) } \\
\hline & $\begin{array}{l}\text { Before } \\
\text { BMP }\end{array}$ & $\begin{array}{l}\text { After } \\
\text { BMP }\end{array}$ & $\begin{array}{l}\text { Before } \\
\text { BMP }\end{array}$ & $\begin{array}{l}\text { After } \\
\text { BMP }\end{array}$ & $\begin{array}{l}\text { Before } \\
\text { BMP }\end{array}$ & $\begin{array}{l}\text { After } \\
\text { BMP }\end{array}$ \\
\hline Fusiforms & $36(92.3)$ & --- & $27(75.0)$ & $3(8.3)$ & $29(80.6)$ & - \\
\hline Pleomorphic G-positive or negative & $36(92.3)$ & $3(7.7)$ & $32(88.9)$ & --- & $12(33.3)$ & - \\
\hline G-positive rods & $34(87.2)$ & $6(15.4)$ & $30(83.3)$ & $2(5.6)$ & $36(100.0)$ & - \\
\hline G-positive v-shape rods & $33(84.6)$ & $4(10.2)$ & $27(75.0)$ & $2(5.6)$ & $29(80.6)$ & $1(2.7)$ \\
\hline Short chains of G-positive cocci & $31(79.5)$ & $1(2.5)$ & $27(75.0)$ & $5(13.9)$ & $36(100.0)$ & $1(2.7)$ \\
\hline G-positive isolated cocci & $31(79.5)$ & $3(7.7)$ & $15(41.6)$ & $5(13.9)$ & $29(69.4)$ & $1(2.7)$ \\
\hline G-negative rods & $31(79.5)$ & --- & $23(63.8)$ & $3(8.3)$ & $31(86.1)$ & - \\
\hline G-positive curved rods & $29(74.4)$ & $3(7.7)$ & $26(72.2)$ & --- & $19(52.8)$ & - \\
\hline G-positive diplobacilli & --- & --- & - & $3(8.3)$ & $8(22.2)$ & - \\
\hline G-positive diplococci & $23(59.0)$ & $3(7.7)$ & $33(91.6)$ & $2(5.6)$ & $2(5.6)$ & $1(2.7)$ \\
\hline Short chains of G-negative cocci & $19(48.7)$ & --- & $1(2.7)$ & --- & --- & - \\
\hline G-positive or negative Chinese letters & $19(48.7)$ & $3(7.7)$ & $18(50.0)$ & --- & $10(27.8)$ & - \\
\hline G-positive filaments & $19(48.7)$ & $3(7.7)$ & $26(69.4)$ & $3(8.3)$ & ------ & \\
\hline G-positive filaments with cocci & $18(46.1)$ & $3(7.7)$ & $21(58.3)$ & $2(5.6)$ & $13(36.1)$ & - \\
\hline G-negative cocci & $18(46.1)$ & $1(2.5)$ & $23(63.8)$ & $1(2.7)$ & $20(55.6)$ & - \\
\hline $\begin{array}{l}\text { G-positive filaments } \\
\text { with cytoplasmic inclusions }\end{array}$ & $18(46.1)$ & --- & $12(33.3)$ & $1(2.7)$ & $12(33.3)$ & - \\
\hline G-negative filaments & $9(23.0)$ & $1(2.5)$ & $23(63.8)$ & $1(2.7)$ & $12(33.3)$ & - \\
\hline Streptococci & $9(23.0)$ & $3(7.7)$ & $9(25.0)$ & - & $8(22.2)$ & - \\
\hline Spirochetes & $4(10.2)$ & --- & $9(25.0)$ & $3(8.3)$ & $1(2.7)$ & - \\
\hline G-negative diplococci & --- & --- & - & --- & $7(19.4)$ & - \\
\hline G-negative diplobacilli & --- & --- & - & --- & $3(8.3)$ & - \\
\hline Staphylococci & $1(2.5)$ & $4(10.2)$ & $1(2.7)$ & $2(5.6)$ & $16(44.4)$ & $1(2.7)$ \\
\hline Curved fusiforms & --- & --- & - & --- & $1(2.7)$ & - \\
\hline $\begin{array}{l}\text { G-negative filaments } \\
\text { with cytoplasmic inclusions }\end{array}$ & $1(2.5)$ & --- & $1(2.7)$ & --- & $9(11.0)$ & - \\
\hline
\end{tabular}

BMP = Biomechanical preparation; $(---)$ = Absent; Outside brackets = Relative frequency; Inside brackets = Absolute frequency .

Table 2. Incidence of positive microbiological cultures and microbial morphotypes before and after biomechanical preparation.

\begin{tabular}{|c|c|c|c|c|}
\hline \multirow[t]{2}{*}{ Groups } & \multicolumn{2}{|c|}{ Before biomechanicalpreparation } & \multicolumn{2}{|c|}{ After biomechanical preparation } \\
\hline & Positive cultures & Number of morphotypes & Positive cultures & Number of morphotypes \\
\hline $\mathrm{I}(\mathrm{n}=39)$ & $39(100 \%)$ & 20 & $10(25.8 \%)$ & 14 \\
\hline II $(n=36)$ & $36(100 \%)$ & 20 & $5(13.7 \%)$ & 15 \\
\hline III $(n=36)$ & $36(100 \%)$ & 23 & $2(6.6 \%)$ & $5 *$ \\
\hline
\end{tabular}

* Statistically significant at $5 \%$. 
Table 3. Incidence of microbial morphotypes before BMP, numbers of root canals, sinus tract and positive microbiological cultures after BMP.

\begin{tabular}{|c|c|c|c|}
\hline Tooth & $\begin{array}{c}\text { Group I } \\
(\mathrm{n}=31)\end{array}$ & $\begin{array}{c}\text { Group II } \\
(\mathrm{n}=32)\end{array}$ & $\begin{array}{l}\text { Group III } \\
\quad(n=30)\end{array}$ \\
\hline 1 & $4^{\#}$ & 11 & 3 \\
\hline 2 & $5^{+}$ & 11 & $11^{+}$ \\
\hline 3 & $3^{+}$ & $9^{\#}$ & $7^{\#}$ \\
\hline 4 & 5 & $9^{+}$ & $9^{*}$ \\
\hline 5 & $6^{*}$ & 8 & 6 \\
\hline 6 & $9^{+}$ & $9^{\#}$ & 9 \\
\hline 7 & 6 & 10 & 12 \\
\hline 8 & $10^{*}$ & $12^{*}$ & 14 \\
\hline 9 & $9^{+}$ & $11^{\#}$ & $10^{*}$ \\
\hline 10 & $10^{\#}$ & 13 & 11 \\
\hline 11 & 10 & $9^{+}$ & $13^{*}$ \\
\hline 12 & $11^{\#}$ & $9^{*}$ & 10 \\
\hline 13 & $9^{+}$ & 9 & 13 \\
\hline 14 & $9^{+}$ & $10^{\#}$ & $12^{*}$ \\
\hline 15 & $8^{\#}$ & 5 & $8^{*}$ \\
\hline 16 & $10^{+}$ & 13 & $10^{*}$ \\
\hline 17 & $11^{+}$ & $4^{+}$ & 9 \\
\hline 18 & 10 & 13 & 12 \\
\hline 19 & 8 & 11 & $11^{\#}$ \\
\hline 20 & $11^{\#}$ & $13^{+}$ & $10^{*}$ \\
\hline 21 & 12 & 11 & $4^{\#}$ \\
\hline 22 & 16 & $2^{*}$ & $11^{*}$ \\
\hline 23 & $15^{\#}$ & $7^{*}$ & $13^{*}$ \\
\hline 24 & 16 & 6 & $12^{\#^{*}}$ \\
\hline 25 & 10 & $13^{+}$ & $14^{+}$ \\
\hline 26 & $9^{+}$ & 9 & 12 \\
\hline 27 & $8^{\#}$ & 10 & $6^{*}$ \\
\hline 28 & 6 & 7 & $11^{\text {*\# }}$ \\
\hline 29 & 4 & 11 & 3 \\
\hline 30 & $6^{\#}$ & 7 & $5^{\#}$ \\
\hline 31 & $9^{+}$ & 5 & -- \\
\hline 32 & -- & 11 & \\
\hline
\end{tabular}

$\mathrm{BMP}=$ biomechanical preparation; ${ }^{*}=$ Tooth with fistula; $\#=$ Tooth with 2 root canals; ${ }^{+}=$Positive culture after BMP.

and Gram-negative bacteria. This microbiological diversity agrees with previous histobacteriological $(1,4)$ and microbial culture studies (8). The role of microorganisms in periapical pathogenesis has been well established and several methodologies have been used to characterize the microbiota in root canals associated with chronic periapical pathology and evaluate the effectiveness of endodontic techniques to eliminate microorganisms from root canals.
It is known that 4 to 7 microbial species on average (and a maximum of 16) can be retrieved per canal using current techniques (4). However, in the present study, the incidence of morphotypes varied from 2 to 16 (9.6 per root canal on average). It is difficult to establish a correlation between the number of microbiological morphotypes and bacterial species. Nevertheless, some authors $(9,10)$ emphasize that to evaluate the intracanal microbiota, Gram stained smears are easy and economical and state that there is a significant correlation with the results of microbiological culture. It must be emphasized that these methodologies show temporal variation. Thus, before BMP, a larger density and diversity of morphotypes in smears, obtained directly from root canals was observed compared to the respective cultures. In contrast, after BMP, the cultures provided smears with a greater density of microorganisms. Such a pattern was possibly be due to the number of microorganisms in the root canals and/or the sensitivity of the methodology used. Therefore, with a large number of microorganisms, the smears tend to be more precise; in contrast, with a small number, preliminary culture improves the observation of viable microorganisms. In this way, the microbiological aspects of the initial smears obtained from root canals were compared to the smears resulting from culture after BMP.

After BMP, an increasing incidence of negative culture can be observed using irrigants of increasing concentration. This is consistent with the findings of a previous in vitro study (11), which showed that an antiseptic solution acts according to the biochemical principle that depends on the concentration of the active element. In this case, it is directly proportional to the concentration of free chlorine, which, in turn, depends on the concentration of hypochloric acid in the solution. This causes a bactericidal effect through oxidation and hydrolysis of sulphide groups of enzymes located on bacterial membranes and cytoplasm (12). Gutiérrez et al. (13) attributed the bactericidal action to plasmosis, in which cuboid crystals of sodium chlorate, the source of $\mathrm{NaOCl}$ (12), close precipitate close to bacteria and is found in dentinal tubules at a depth of up to $220 \mu \mathrm{m}$.

No significant differences were found between the negative microbiological cultures and the different $\mathrm{NaOCl}$ concentrations. Perhaps, less concentrated solutions used copiously and frequently have their antimicrobial effect increased, becoming as clinically effective as $5 \% \mathrm{NaOCl}$. Because all solutions were used in 
the same way and under similar clinical conditions, $5 \%$ $\mathrm{NaOCl}$ would have a better antiseptic performance (i.e., produce $100 \%$ negative microbiological culture), which did not occur, suggesting that variable concentration, frequency and volume have a limited enhancing effect on the antiseptic efficacy of irrigants. This limit corresponds to its maximum clinical efficacy, which, once reached, cannot be increased significantly by either the amount applied after each file, the active ingredient concentration or the increase of irrigation frequency.

After BMP, the incidence of negative microbiological culture was not significantly influenced by the concentration of irrigants. The solutions presented a similar antisepsis pattern against Gram-negative and positive microorganisms. However, $5 \% \mathrm{NaOCl}$ was significantly more effective against Gram-positives. Sydney and Estrela (14) showed that Gram-negative bacteria were more sensitive to BMP, while the Grampositive bacteria were more resistant, with the highest incidence of Peptostreptococcus prevoti and Clostridium histolyticum. After BMP and placement of calcium hydroxide-based intracanal dressings in dogs' teeth with induced chronic periapical lesions, Soares et al. (1) observed a predominantly Gram-positive microbiota in the root canal system. The different susceptibilities of microorganisms may be partially attributed to the composition and structure of their cell walls. Thus, although the cell wall of Gram-negative bacteria is more complex, containing glycopeptides, lipoproteins, an external membrane and lipopolysaccharides, apparently the cell structures of Gram-positive microorganisms offer greater resistance to endodontic procedures, possibly determined by the structure of glycopeptides in the cell wall, which is thicker in Gram-positive microorganisms.

The incidence of morphotypes in the canals of teeth with fistulas varied from 3 to 16 (9.8 on average) versus 2 to 15 (9.5 on average) for teeth without fistulas. This raises the possibility that the occurrence of a fistula is independent on the number of morphotypes in the root canal and may be dependant on the interaction between certain bacterial species and the host's immunological system $(4,8)$. All 18 teeth with associated sinus tracts were microbiologically negative after BMP. In part, it may be attributed to the fact that 12 teeth $(66.6 \%)$ had their canals irrigated with $5 \% \mathrm{NaOCl}$, which increased the chances of eliminating the microbiota.

Perhaps the antiseptic effect of irrigants also correlates with the ability to remove debris from the root canals, which, in turn, is influenced, not only by the concentration of the active ingredient, but also by the quantity and frequency of irrigation as well as the amount of root canal enlargement. Nery et al. (15) demonstrated that the ability to remove debris lodged in the apical third depends much more on the frequency of using an irrigating solution than on the technique of irrigation or the type of irrigating solution used, while Orstavik et al. (16) highlighted the importance of widening the root canal. The influence of the time that the irrigating solution remained in the root canal may explain why all teeth with 2 roots produced negative cultures irrespective of the irrigants solution used because the time for irrigation and instrumentation was practically twice as long as that spent for a single-rooted tooth.

The irrigants showed a varying effect on the microbial forms. Thus, some morphotypes were reduced or even eliminated, a result that increased with higher concentrations of free chlorine but not always. This uneven pattern of endodontic microbiota susceptibility to BMP has been shown.It has been reported (8) that microbiological samples obtained after BMP plus $2.5 \% \mathrm{NaOCl}$ revealed that, numerically, some species were reduced, some increased and others remained the same. However, in our study, $5 \% \mathrm{NaOCl}$ had a more specific antiseptic effect because it eliminated $77.3 \%$ of the identified morphotypes. Therefore, the root canal microbiota can be significantly altered by the preparation of teeth with necrotic pulp associated with radiolucent periapical areas using $5 \% \mathrm{NaOCl}$ as irrigant. In contrast, the use of chlorine solutions in lower concentrations immediately followed by root canal obturation often leads to failure because of the persistence of radiolucent areas is associated with a high incidence of Gram-positive cocci and bacilli, distributed in the root canal and apical cementum lacunae, which are responsible for marked periapical tissue disorganization (17).

In addition to giving the main root canal a conical shape, BMP has other advantages. Each milligram of necrotic tissue removed contains $10^{7.7} \pm 0.6$ microorganisms on average (18). However, the canals cannot be immediately obturated after BMP even if associated with copious irrigation because no antiseptic solution has provided $100 \%$ negative culture (19). Moreover, file action and irrigant nature are limited by irregularities in root canal anatomy that may lodge microorganisms. Therefore, 48 to $96 \mathrm{~h}$ after BMP, the remaining microorganisms proliferate and are capable of re-establishing 
the previous pattern of colonization $(1,14,19)$.

From a microbiological standpoint, the main root canal and its ramifications should receive the best disinfection protocol possible. Several calcium hydroxide-base dressings have been recommended with this objective $(1,4,20)$. Although the gas requirements for obligatory anaerobes were not used, the results of this study suggest that, in terms of negative microbiological culture, the antiseptic efficacy of irrigants was not influenced by their concentration. Regarding the elimination of microbiological morphotypes, only $5 \% \mathrm{NaOCl}$ had a strong impact on root canal microbiota because in the few positive microbiological cultures a significant reduction was shown in the microbiological morphotypes. Therefore, BMP with use of $5 \% \mathrm{NaOCl}$ will reduce the number of microorganisms in the main root canal for the intracanal dressing to eliminate.

\section{RESUMO}

Este estudo avaliou as condições microbiológicas dos canais radiculares, por meio de esfregaços e culturas de dentes anteriores e pré-molares com necrose pulpar associada à radiolucidezes periapicais, antes e após o preparo biomecânico (PBM). Utilizouse a técnica de instrumentação biescalonada coadjuvada por soluções de hipoclorito de sódio $(\mathrm{NaOCl})$ a $1,2,5$ ou $5 \%$ nos grupos I $(n=39)$, II $(n=36)$ e III $(n=36)$, respectivamente. Antes do PBM havia $100 \%$ de culturas positivas e os esfregaços proveram diversificados morfotipos microbiológicos, sendo 20 , 20 e 23 nos grupos I, II e III, respectivamente. Após o PBM, o percentual de culturas negativas nos grupos I, II e III foi 74,2\%, 86,3 e $93,4 \%(p>0,05)$ e a incidência de morfotipos declinou para 14,15 e 5 , respectivamente. Todos os dentes birradiculados e/ou portadores de fístulas apresentaram-se microbiologicamente negativos após o PBM, independentemente do irrigante utilizado. Os morfotipos Gram-negativos foram mais suscetíveis à ação do PBM. Após o PBM persistiram apenas cocos e bacilos Grampositivos no grupo III. Portanto, o PBM coadjuvado por solução de $\mathrm{NaOCl}$ a $5 \%$, proporcionou o melhor desempenho anti-séptico, pois, nas poucas culturas positivas, houve também significativa redução do número de morfotipos microbiológicos $(\mathrm{p}<0.05)$.

\section{REFERENCES}

1. Soares JA, Leonardo MR, Silva LAB, Tanomaru Filho M, Ito IY. Effect of biomechanical preparation and calcium hydroxide pastes on the anti-sepsis of root canal systems in dogs. J App Oral Sci 2005;13:93-100.

2. Debelian GJ, Olsen I, Tronstad L. Bacteremia in conjunction with endodontic therapy. Endod Dent Traumatol 1995; 11:142-149.

3. Sundqvist G. Ecology of the root canal flora. J Endod 1992; 18:427-429.

4. Soares JA, Leonardo MR, Silva LAB, Tanomaru Filho M, Ito
IY. Effect of rotary instrumentation and of the association of calcium hydroxide and chlorhexidine on the anti-sepsis of root canal systems in dogs. Braz Oral Res 2006;20:120-126.

5. Molven O, Olsen I, Kerekes K. Scanning electron microscopy of bacteria in the apical part of root canals in permanent teeth with periapical lesions. Endod Dent Traumatol 1991;7:226-229.

6. Sen BH, Piskin B, Dermirci T. Observation of bacteria and fungi in infected root canals and dentinal tubules by SEM. Endod Dent Traumatol 1995;11:6-9.

7. Nair PNR. Light and electron microscopic studies of root canal flora and periapical lesions. J Endod 1987;13:29-39.

8. Gomes BPFA, Lilley JD, Drucker DB. Variations in the susceptibilities of components of the endodontic microflora to biomechanical procedures. Int Endod J 1996;29:235-241.

9. Pajari U, Ahola R, Backman T, Hietala EL, Tjäderhane L, Larmas M. Evaluation of Gram's method of staining for the prognosis of root canal treatment in nonvital dental pulps. Oral Surg Oral Med Oral Pathol 1993;76:91-99.

10. Kuruvilla JR, Kamath P. Antimicrobial activity of $2.5 \%$ sodium hypochlorite and $0.2 \%$ chlorhexidine gluconate separately and combined, as endodontic irrigants. J Endod 1998;24:472-475.

11. Yesilsoy C, Whitaker E, Cleveland D, Phillips E, Trope M. Antimicrobial and toxic effects of established and potential root canal irrigants. J Endod 1995;21:513-515.

12. Siqueira Jr JF, Batista MMD, Fraga RC, Uzeda M Antibacterial effects of endodontic irrigants on Black-pigmented Gramnegative anaerobes and facultative bacteria. J Endod 1998;24:414-416.

13. Gutiérrez JH, Jofré A, Villena F. Scanning electron microscope study on the action of endodontic irrigants on bacteria invading the dentinal tubules. Oral Surg Oral Med Oral Pathol 1990;69:491-501.

14. Sydney GB, Estrela C. Influence of root canal preparation on anaerobic bacteria in teeth with asymptomatic apical periodontitis. Braz Endod J 1996;1:7-10.

15. Nery MJ, Holland R, Souza V. Efficacy of different irrigating techniques and irrigants for removal of debris from root canals. Rev Odontol Araçatuba 1982;3:21-27.

16. Orstavik D, Kerekes K, Molven O. Effects of extensive apical reaming and calcium hydroxide dressing on bacterial infection during treatment of apical periodontitis: a pilot study. Int Endod J 1991;24:1-7.

17. Leonardo MR, Almeida WA, Ito IY, Silva LAB. Radiographic and microbiologic evaluation of postreatment apical and periapical repair of root canals of dog's teeth with experimentally induced chronic lesion. Oral Surg Oral Med Oral Pathol 1994;78:23-28.

18. Zavistoski J, Dzink J, Onderdonk A, Bartlett J. Quantitative bacteriology of endodontic infections. Oral Surg Oral Med Oral Pathol 1980;49:171-174.

19. Sjögren U, Fidgor D, Persson S, Sundqvist G. Influence of infection at the time of root filling on the outcome of endodontic treatment of teeth with apical periodontitis. Int Endod J 1997;30:297-306.

20. Soares JA, Leonardo MR, Silva LAB, Tanomaru Filho M, Ito IY. Elimination of intracanal infection in dogs' teeth with induced periapical lesions after rotary instrumentation: Influence of different calcium hydroxide pastes. J Appl Oral Sci. 2006;14:172-177. 